\title{
Accessing Self-Control
}

\author{
Polaris Koi ${ }^{1}$ (D)
}

Received: 18 June 2020 / Accepted: 24 November 2021

(c) The Author(s) 2021, corrected publication 2022

\begin{abstract}
Self-control is that which is enacted to align our behaviour with intentions, motives, or better judgment in the face of conflicting impulses of motives. In this paper, I ask, what explains interpersonal differences in self-control? After defending a functionalist conception of self-control, I argue that differences in self-control are analogous to differences in mobility: they are modulated by inherent traits and environmental supports and constraints in interaction. This joint effect of individual (neuro)biology and environmental factors is best understood in terms of access to self-control behaviours. I sketch an account of access as including the three criteria of means, awareness, and non-excessive effort. I further demonstrate that people with disorders such as ADHD have limited access to self-control behaviours and stand therefore at a disadvantage with regard to self-control.
\end{abstract}

\section{Introduction}

Self-control is that which is enacted to align our behaviour with a motivational commitment, such as an intention or better judgment, in the face of conflicting impulses of motives ${ }^{1}$. It is an umbrella concept, subject to various measures that are distinct but correlated (Duckworth \& Kern, 2011). We enact self-control, e.g., to quit intrusive habits and begin new ones, to put down a novel to do the dishes, and to refrain from shouting at a loved one when angry.

Some people seem to have more self-control than others: for example, Miguel seems to have an easier time aligning his actions with his better judgment than Rafael, who often finds himself doing something he would not endorse, such as shouting at his mother or putting off doing something he intends to do. Measures

\footnotetext{
1 This choice of phrasing is not intended as a commitment to enactivism but rather is used in the sense of brought to pass, effected, executed, deployed, engaged in.

Polaris Koi

polaris.koi@utu.fi

1 Philosophy Unit, University of Turku, 20014 Turku, Finland
} 
such as the trait self-control scale have been developed in psychology to study the various correlates of individual variation in self-control. ${ }^{2}$ Yet Miguel, too, sometimes fails in self-control: for example, while he usually refrains from beef to protect the environment, he sometimes succumbs to the temptation of a freshly grilled steak. Vice versa, it is not unusual for Rafael to succeed in self-control.

Often, successes and failures in self-control are seen as personal successes and failures. We commend Miguel for his self-controlled character. We likewise think Rafael's persistent troubles in self-control are a personal failure of his and treat his successes in self-control as evidence that had he flexed his 'mental muscle' ${ }^{3}$ a bit more, he could have done better at other occasions, as well. I argue that this is mistaken. Rather, self-control depends on whether one has access ${ }^{4}$ to such behaviours that serve its function. There is interpersonal variation in the extent to which various processes and strategies are feasible to us, and in the extent to which we are aware of these forms of self-control. When an agent lacks means $\mathrm{M}$ to enact self-control, is not aware of $\mathrm{M}$, or when $\mathrm{M}$ requires excessive effort, that agent does not have access to self-control. I have previously gestured towards this radically externalist view of self-control (Koi, 2021); here, I develop it more fully.

To make my case for an access-based account of individual differences in selfcontrol, I must first argue for self-control as subject to multiple realizability, defined by its behavioural function rather than by the presence of any specific mental process or mechanism. However, as I will point out, those who are not persuaded by such a functionalist account of self-control can still adopt a restricted form of the access account.

In this paper, my first order of business is to establish that exercises of self-control are constituted by a heterogeneous set of behaviours (including both mental and overt behaviours), pooled together by their applicability to the direction of behaviour $^{5}$ to match intention. Given their heterogeneity, the environment has a central epistemic and constitutive role in these behaviours. In Sect. 2, I argue for such a functionalist approach to self-control by showing that a 'process' view of selfcontrol, such as is found in Sripada (2020), must posit a further feature in virtue of which those processes are self-control, and that a 'results' view such as the one defended here provides just that. Further evidence is provided by findings in social psychology, which indicate that skill in self-control tracks the deployment of a variety of strategies.

\footnotetext{
2 The trait self-control scale (Tangney, Baumeister \& Boone 2004) predicts success in multiple domains of self-control. It is correlated with but distinct from other measures, such as various measures of inhibitory control and delayed gratification (Duckworth \& Kern 2011). See Levy (2017) for an account of trait self-control as crucially involving environmental practices.

3 The concept of self-control as a 'mental muscle' was popularized by Roy Baumeister (Muraven \& Baumeister 2000, Baumeister \& Exline 1999, Baumeister, Vohs \& Tice 2007).

4 Not to be confused with the concept of epistemic access.

5 In this paper, I speak much of behaviour. This is not to be taken to imply a covert commitment to Skinnerian radical behaviourism. It is simply used as a term that refers to both intentional and unintentional actions, movements, reflexes, etc.
} 
In Sect. 3, I analyse the concept of access as consisting of means, awareness and non-excessive effort. I show that the presence and absence of environmental constraints and supports modulate the presence of feasible means of self-control, as well as awareness of them. As a result, interpersonal and diachronic differences in self-control are a result of differences in environmental access to self-control behaviours, ${ }^{6}$ rather than just a result of innate individual differences. To have a capacity for self-control, for this stance, is to have access to self-control behaviours. It follows that the extent to which one has the capacity for self-control critically hinges on the extent to which they have access to self-control behaviours, and that it is commonplace for access to self-control to be unevenly distributed in ways that favour agents with certain innate and social traits over others. However, this contingency can be significantly ameliorated. Individual differences in self-control thus become a matter of justice.

Finally, in Sect. 4, I demonstrate the practical upshots of the access theory and how it can be applied to particular cases by analysing attention-deficit hyperactivity disorder (ADHD) as a case where access to self-control is limited.

\section{Self-Control is a Broad Set of Behaviours}

Accounts of self-control in both philosophy and social psychology are highly varied. If there is a consensus, it is that self-control is that which enables one to resolve a motivational conflict and act accordingly: to inhibit a prepotent impulse in order to act intentionally, to follow one's judgment rather than desire, or to forgo a smaller, sooner reward to pursue a larger, later goal. ${ }^{7}$ Sometimes these motivational conflicts further map onto a conception of the mind as divided, e.g., between reason and appetite, or between hot and cool processes. ${ }^{8}$ Another compatible conception holds self-control to be roughly equivalent with inhibitory control and describes it as an intramental mechanism, often reducible to the brain ${ }^{9}$; sometimes, this mechanism is associated with a mysterious faculty dubbed 'willpower'. Sripada (2020) paints the debate in terms of process views of self-control, which define self-control as a specific process, and results views, for which self-control is defined by its 'result'

\footnotetext{
${ }^{6}$ Some failures of self-control are such that an agent chooses not to control themselves, i.e., that she chooses not to enact self-control behaviours. The causes of these motivational failures are beyond the scope of this article; in any case, it is a different question than what I am probing here, which has to do with self-control at the level of efficacy rather than intentionality.

7 Examples include Mele (1987, 1995) and Kennett (2001), who each characterize self-control in terms of judgment versus desire; and Ainslie (2001) and Fujita (2011) who define it in terms of smaller sooner versus larger later rewards.

8 For divided mind accounts, see Levy (2011), where self-control is defined in terms of 'hot' system 1 processes vs 'cool' system 2 processes, Sripada (2014), who divides the mind to a deliberative motivational system and an emotional motivational system, and Kalis (2018), who defends the rationality over appetites view. Fujita, Carnevale \& Trope (2018) offer an alternative to the divided mind approach, suggesting a model where self-control succeeds when a unified 'whole' self gets its way.

9 See, for example, Cohen, Berkman \& Lieberman (2013), who define self-control as inhibitory impulse control, and describe self-control as a function of the right ventrolateral prefrontal cortex.
} 
or behavioural output and can be realized by a variety of processes, skills, and strategies. ${ }^{10}$

Within self-control research, the suppression of unwanted impulses with 'brute' inhibition is often treated as a benchmark form of self-control against which other forms of self-control are compared. However, inhibitory control should not be equated with self-control. This is because inhibitory control processes are not specific to self-control, but are also present for other tasks that do not involve motivational conflict. Instead, they undergird much of skilled action, such as baseball batting (Gray, 2009). In other words, there must be a further feature in virtue of which some instances of inhibition count as self-control. And if there is something in virtue of which some instances of inhibition count as self-control, then could not other processes and mechanisms also count as self-control if they share that feature?

The view put forth in this section is that the feature in virtue of which some processes count as self-control is the behavioural function of these processes; that a range of processes and behaviours share this function; and that a range of functionally equivalent behaviours and processes therefore count as self-control.

In this paper, I define self-control by its behavioural function, which is the regulation of output to match motivational commitments such as intentions, plans, and the like. In brief, self-control is that which is enacted to align behaviour with intention, better judgment, or other motivational commitment in the face of a concurrent or expected competing motivation.

For this account, then, self-control simply is whatever fulfils this behavioural function; it falls under results views in Sripada's taxonomy.

The regulation of output to match intention is arguably the prototypical domain of self-control for this account. However, on accounts of intention that distinguish it from other sorts of motivational commitments (e.g., Audi, 1991), the behaviours that enable matching output to intention also enable matching output to other sorts of motivational commitments such as plans and (for those who view self-control in terms of evaluative processes) preference or better judgment. On some accounts of intention and the relationship between motivation and action, self-control may occur in service of a commitment other than intention. In what follows, I will speak of conformity to intention for simplicity, but allow for self-control to also occur in service of other sorts of motivational commitments.

Take Miguel, who upon dining out grapples with the temptation to order steak. After rehearsing his reasons to forgo beef, he orders the more climate friendly dish. For the view espoused here, this is a success in self-control because Miguel, upon observing or expecting a competing motivation (to eat steak) enacted something (rehearsed reasons) to modulate behavioural output so as to conform with Miguel's intention (to forgo beef). Rafael, by contrast, loses his patience at family dinner and shouts at his mother despite having resolved to keep his

\footnotetext{
10 By my lights, it would be more informative to speak of the function of self-control than of its results, as the heart of the results views, in my view, is to treat behaviours that are functionally equivalent as falling within the scope of the same concept; for the purposes of this paper however, it does no harm to follow Sripada's terminology.
} 
cool. This counts as a failure of self-control because the behavioural output has not conformed with Rafael's intention to stay calm, but rather, with a contrary motivation.

In addition to the present paper, results views have been defended by Levy (2017) and, in social psychology, gestured towards by Duckworth et al. (2016) with what could be called the argument from efficacy. For this line or argument, if processes such as inhibitory control and attention regulation count as self-control because they regulate behaviour in the face of a motivational conflict, presumably the processes that most reliably achieve this regulatory purpose should count as paradigmatic instances of self-control. If behaviours and processes other than inhibitory control turn out to be equally or more effective than inhibitory control in regulating behaviour in the face of a motivational conflict, then this raises the question why we should think of processes such as inhibitory control as the benchmarks of selfcontrol in the first place.

To illustrate the breadth of behaviours that, for my account, are functionally equivalent, I follow Duckworth et al. (2016) rough division of the pool of selfcontrol behaviours into situational strategies and intrapsychic strategies. Situational strategies include situation selection and situation modification. Situation selection involves avoiding the presence of an unwelcome temptation altogether. For example, Miguel, scheduling a family dinner, might choose a vegetarian restaurant instead of a steakhouse in order to stick to his resolution to avoid beef. In that case, Miguel is anticipating a motivational conflict, and enacts a behaviour (reserving a table at the vegetarian restaurant) to align his future behaviour with his intention.

Situational modification refers to behaviours undertaken within a situation to alter its physical and social features in a way that facilitates resolving the anticipated or concurrent motivational conflict in favour of intention rather than conflicting motivation. For example, if Miguel is having dinner at a steakhouse, he might ask his dinner party to order him a salad so that he does not need to look at the tempting menu; or a professor striving to write an article but being tempted to scroll social media might unplug their wi-fi router. In these cases, again, a motivational conflict is experienced or anticipated, and a behaviour (asking others to order, unplugging the router) is enacted to align subsequent behaviour with intention.

Situational strategies are not always readily available; for example, in the Stanford experiments in delayed gratification (Mischel \& Ebbesen, 1970), children placed in a room with a treat did not have the option of leaving the room or otherwise altering the physical or social setup of the experiment. This leaves room for intrapsychic strategies of self-control (Duckworth et al., 2016). These are comprised of attention deployment (such as self-distraction), cognitive change (such as via construal or rehearsing one's reasons), and response modulation (including the suppression of impulses).

Intrapsychic strategies have been documented to be effective in delayed gratification tasks. For example, Mischel and Ebbesen (1970) observed that self-distraction was a predictor of success in delayed gratification. In addition to self-distraction, later work suggested that construal plays a similar key role. While children can spontaneously come up with these strategies, these can also be taught, which improves performance in subsequent delayed gratification tasks (Mischel et al., 2011). 
In Levy's (2017) analysis, skills and strategies such as self-distraction, construal, and situation selection count as self-control because they predict success in pursuing larger later rewards. ${ }^{11}$ Noting that situation selection has been found to be positively correlated with measures on the trait self-control scale, but people high on trait selfcontrol were not found to do better in ego depletion tasks, ${ }^{12}$ Levy (ibid.) suggests that the trait self-control scale may measure skill in environmental strategies of selfcontrol. A similar conclusion can be found in Duckworth et al. (2016), in whose analysis intrapsychic strategies, while effective, are not as effective in producing the desired behaviour as environmental strategies. ${ }^{13}$

At first brush, describing self-control as a heterogeneous set of behaviours may seem at odds with describing it as a capacity subject to interpersonal differences. It is certainly not a dedicated capacity if such a broad pool of behaviours is involved. Instead, it is a capacity in the same broad sense as mobility is a capacity: in the sense that there are individual differences in the extent to which people can realize the sorts of behaviours that serve the function demarcated by the self-control construct. The availability of these behaviours is also subject to diachronic variation, which explains diachronic differences in self-control: Miguel's self-control may fail when he finds himself in an environment where his ordinary self-control behaviours cannot be readily enacted, and Rafael may be more successful in self-control in certain situations where salient means for self-control are present. ${ }^{14}$

The functionalist approach defended here is controversial in that it allows for any process that fulfils the behavioural function of self-control to count as self-control. By contrast, for some views, such as willpower theories and for the mechanistic process view described by Sripada (2020), self-control is either a single dedicated mental faculty, process, or mechanism, or else a narrowly defined set of such. The behavioural output, for such accounts, is a downstream effect of such a mechanism or process.

\footnotetext{
${ }^{11}$ I have some reservations concerning thinking of self-control in terms of larger later rewards only as that introduces an evaluative dimension to self-control that in my view is unnecessary; however, this is a distinction that is of no consequence to the argument presented in this article.

12 See Imhoff, Schmidt \& Gerstenberg 2014 and Baumeister, Ent \& Tice 2015 for the experiments, and Levy 2017 for an analysis of their implications for self-control.

${ }^{13}$ The distinction between situational and intrapsychic strategies is not clear-cut: for example, it is not clear whether attention deployment strategies deployed in the Stanford experiments, such as turning one's back to the marshmallow or singing, fall within the situational or intrapsychic group. The distinction is simply meant to illustrate the heterogeneity of functionally equivalent self-control practices. These blurred lines are not a problem for the functionalist view of self-control, as the distinction does no work for that conception. However, the fact that attentional shifting and construal are often enacted in such an embodied manner does generate some difficulty for those who wish to maintain intrapsychic heterogeneity of self-control practices as including not just brute inhibition but also processes like attentional shifting and construal, while excluding situational strategies from the scope of the concept of self-control.

14 While I claim that all interpersonal variation in self-control is best explained by differences in access, I do not claim that that all single instances of self-control failure would be so explained. Some failures happen due to arbitrary factors, such as neuronal noise (Stein, Gossen \& Jones 2005), which renders all processes that involve the nervous system subject to some variability that agents cannot control for. These processes may cause a blunder in self-control even in the ideal circumstances, although I am agnostic as to how common this is.
} 
Willpower theories of self-control ${ }^{15}$ are perhaps the best-known contemporary process accounts of self-control. Inspired by Aristotelian accounts of akrasia and enkrateia on one hand and by theories in social psychology on the other, they posit that what distinguishes self-control from other faculties is that it relies on a dedicated mental faculty. This mental faculty has been associated with the executive functions. Some willpower theorists make the additional claims that willpower, far from being a mere mechanism, is a discrete faculty that can be developed, exercised, and consciously exerted; and that it fatigues or becomes depleted when used, much like a muscle. ${ }^{16}$

Yet the willpower approach faces numerous problems. Chief among these is that willpower accounts struggle to explain diachronic variation in self-control: it is puzzling how people with high willpower at a given time fail at self-control at another time, and vice versa, how people low in willpower at one time manage to succeed in it at another. Failures of self-control have been accounted for, in some willpower theories, by reference to the ego depletion hypothesis according to which willpower involves a limited, dedicated resource that is depleted with use; this hypothesis has faced copious criticism, including due to replication issues. ${ }^{17}$

In response to these problems, those unwilling to adopt a results view of selfcontrol have taken pains to revise the notion that self-control refers to a dedicated mechanism or process by clarifying it, setting aside ego depletion theories in favour of a different theoretical approach. Sripada (2020) offers such a revision, executed in admirable detail. For Sripada (2020), self-control consists in a skilled, extended sequence of cognitive control aimed at regulating responses associated with an unwanted motivational state (or emotion-type state, to use Sripada's terminology).

However, Sripada's account, while nuanced, raises the question why some such extended sequences of control count as self-control. After all, extended sequences of cognitive control aimed at regulating responses are not sufficient for something to be self-control, given that such extended regulation is present in much of skilled action. There must therefore be something further in virtue of which it counts as self-control. Sripada would likely concur: he reminds us that"an exercise of selfcontrol doesn't consist of just any arbitrary sequence of cognitive control actions. It is rather a sequence that manifests the appropriate sort of knowing how to block the actional upshots of an emotion-type state" (Ibid., p. 14, italics in the original). But if such a sequence counts as self-control because it skilfully blocks actional upshots,

\footnotetext{
${ }^{15}$ In philosophy, willpower theories have been advocated, e.g., by Henden (2008) and Holton (2003); Holton, however, denies that weakness of will would be akrasia.

${ }^{16}$ In social psychology, perhaps the most prominent willpower theorists have been Roy Baumeister and colleagues (e.g. Muraven \& Baumeister 2000, Baumeister \& Exline 1999, Baumeister, Vohs \& Tice 2007).

${ }^{17}$ For a report of a preregistered multilaboratory replication attempt which showed no effect for ego depletion, see Hagger et al. (2016). A recent replication by Kathleen D. Vohs (one of the originators of the ego depletion hypothesis) and colleagues likewise showed no effect (Vohs et al., 2021). A prominent methodological conundrum for the study of ego depletion is that it is difficult, within experimental settings, to distinguish the proposed ego depletion effect from the effects of fatigue. For an overview of the current state of the debate, see Inzlicht \& Friese (2019).
} 
this raises the question why should we think of self-control as necessarily involving such a sequence, rather than thinking of such a sequence as an accidental property of many instances of self-control? One reason to prefer a results view, then, is that it explains why Sripada's formulation is an apt description of many instances of selfcontrol, while allowing self-control to be subject to multiple realizability.

Results views are not without their critics. In the remainder of this section, I offer some responses to criticisms that target results views of self-control, including the functionalist conception defended here.

1. Results views are normative or arbitrary. The startling heterogeneity of behaviours and processes labelled self-control in the results view has given rise to charges that self-control would be either a nonsensical category, the contents of which are arbitrary, or else a normative construct held together by the normative valence we give to self-controlled behaviour. ${ }^{18}$ However, pooling the various behaviours and processes together by their behavioural function is neither normative nor arbitrary.

2. Functionalist concepts are useless for science. For this objection, describing self-control as a heterogeneous set of behaviours makes it a concept well suited for lay and philosophical conversations but hard for empirical scientists to operationalize. I agree, but I do not believe this poses a problem: empirical scientists can focus their research on specific behaviours or their specific correlates, as they have to date. In terms of continued empirical research, I merely urge a cautious acknowledgement that these operational targets of research represent but some of the many possible mechanisms and behaviours that self-control may encompass.

3. Results views yield conclusions that are unintuitive or that do not match everyday language. Sripada's (2020) chief objection to results views is that according to them, some behaviours count as self-control that do not intuitively strike us as such, and that we do not routinely label as self-control in everyday conversation. Sripada illustrates this with a range of cases. One these is that of Bo, who has an itchy rash on his arm that he intends not to scratch. In order to squash the contrary motivation to scratch the itch, Bo applies lotion on the rash and the urge to scratch goes away. Sripada's pre-theoretical view is that this "is clearly not an exercise of self-control" (2020: p. 18), despite that for results views it clearly is such. Sripada's reasoning is that Bo gets the results too easy and too fast, and should have to struggle with the urge for an extended period of time for his behaviour to count as self-control. Here, one may counter with the charge that gratuitous cognitive effort is not, pretheoretically, self-control either. If, after Bo's rash naturally stops itching, Bo rubs vinegar on it, causing it to itch again so that he can continue to resist the urge to scratch it, describing this gratuitous activity as self-control does not seem well in line with our everyday usage of the self-control concept. In light of this, it is unclear why the gratuitous struggle caused by abstinence from lotion would count as self-control, either.

\footnotetext{
18 The arbitrariness claim is made by Herdova (2017), whereas the normativity claim is argued for by Kalis (2018) and Horstkötter (2015).
} 
In other words, neither process accounts nor results accounts fully track all everyday language usage, and that both can be mined for counterintuitive cases. This shouldn't be a problem for philosophy or psychological theory, however. While our analyses of concepts like self-control should have robust overlap with everyday usage (or else we risk analysing an altogether different construct), it should also be expected that philosophical analyses sometimes yield results that urge us to revise our pre-theoretical notions.

Sripada's most persuasive case is that of a self-control pill. By eating this pill, an agent thwarts an anticipated urge to smoke. (ibid.) For Sripada, this is counterintuitive because we intuitively expect self-control to always involve effort, and the agent has it too easy. While I agree that this case is counterintuitive, I am entirely willing to bite the bullet. Sometimes enacting self-control is easy; sometimes it is hard; sometimes it takes forms that, pre-theoretically, seem odd to us. However, not all medication aimed at regulating behaviour is self-control: for a behaviour, such as the ingestion of a pill, to count as self-control it needs to be aimed at a current or anticipated motivational conflict. ${ }^{19}$ For this reason, e.g., medication used to treat ADHD, though helpful, is not self-control for the functionalist view.

In light of the above discussion, I maintain that self-control is best conceived of as a broad set of behaviours united by their behavioural function. While controversial, this view gives us a conception of self-control that is conceptually coherent and matches existing information in social psychology concerning how, in practice, agents regulate their behaviour in the face of motivational conflicts.

I next describe my account of individual differences in self-control as resulting from differences in access to self-control behaviours. While the functionalist view of self-control described above gives the access account the widest consequences, those who are not persuaded by the above discussion can still accept a weaker version of the access account described below.

\section{Which Self-Control Behaviours are Accessible?}

That there is a heterogeneous pool of self-control behaviours rather than one such behaviour is fortunate, because it enables substituting one behaviour for another based on which strategies of self-control are a good fit for a given agent and their context. For example, a student sitting in an exam and noticing that her attention is wandering to an attractive classmate cannot physically remove herself from the space without forfeiting the exam, but she may attempt intramental strategies of self-control, as described above. In theory, almost any agent, including agents with cognitive and learning disabilities, could possess a robust 'toolkit' of self-control behaviours that are a good fit for them, and select a means out of that set based on contextual fit. In this section, I argue that individual differences in self-control

\footnotetext{
19 We should also remember that thought experiments do not always yield reliable intuitions: in a world where such pills as Sripada describes were readily available, our intuitions surrounding these might be very different.
} 
are best conceived of in terms of access to self-control behaviours. Differences in self-control, for this account, arise from barriers in the social environment. These barriers make many such behaviours unfeasible and therefore unsuitable as means to self-control. Furthermore, epistemic barriers prevent many agents from learning or becoming aware of suitable means to self-control. Unjust structures of the social and built environment thus result in aggravated individual differences in self-control.

My discussion of access draws from recent philosophical work on disability, ${ }^{20}$ which has brought attention to the way many disabilities disable not merely because of physiological differences between, for example, wheelchair users and those who walk, but also due to the various barriers the environment places on the former. The social and built environment, for these accounts, generates differences in the extent to which spaces, services, activities and the like can be accessed, providing access for some but not for all.

For example, wheelchair users have a hard time getting around in a world designed for people who walk, but this is not an intrinsic feature of the person using the wheelchair: rather, the environment is structured in such a way that helps others get around, such as by providing stairs, while hindering the wheelchair user from doing so, such as by omitting ramps and elevators, by placing them inconveniently, and by making it hard to find out where these are located. In brief, the environment contingently favours people with certain physiological traits, ${ }^{21}$ granting some a capacity to get around while placing obstacles on others. From this, it has been inferred that physical disabilities are not fully inside our bodies. The environment also plays a constitutive role in them.

However, despite a focus on the social and built environment in the study of disability and a near-ubiquitous adoption of accessibility measures as policies of inclusion, the concept of access or accessibility has not been the topic of systematic philosophical analysis. For my purposes here, it is sufficient to sketch out access as having three central criteria. These criteria are:

1. Means. For an agent $\mathrm{A}$ to have access to a space, behaviour, or practice $\mathrm{X}$, there must be a concrete means $\mathrm{M}$ by which $\mathrm{A}$ is able to $\mathrm{X}$ (given A's traits).

For example, for many people, walking up stairs is such a means $\mathrm{M}$ in accessing a meeting room on the $3^{\text {rd }}$ floor. But that is not such a means $M$ for wheelchair users. Ramps and elevators would be such a means for a larger group of people.

\footnotetext{
20 See, e.g., Oliver (1996), Barnes (2016), Shakespeare (2008), Tremain (2015). While there is disagreement among these philosophers about the precise nature of philosophy and the extent to which disability is socially constituted, they agree that the social and built environment plays a considerable role in disabling people with certain biological traits.

21 The social model of disability (Oliver 1996) distinguished between impairments and disabilities, the former being the innately disadvantageous, biological foundation on which social stigma and physical barriers build the latter. In what follows, I will refer to traits rather than impairments because in many cases, the traits at hand do not themselves impair: they may be mere differences. (This is not true for all traits - e.g., chronic pain is itself obstructive for many life plans.) See Tremain (2015) for an analysis of the concept of impairment.
} 
2. Awareness. The agent must be aware of the concrete means $\mathrm{M}$ by which they can $\mathrm{X}$.

For example, the location of the ramp or elevator must be known or immediately salient to A.

3. Non-excessive effort. The effort it takes for A to $\mathrm{M}$ needs to not be excessive.

For example, if the ramps are located at the other side of a large building complex, the effort a wheelchair user must expend to get to the 3rd floor is excessive. Likewise, many people with limited mobility are able to use stairs but not without excessive effort; in such a case, stairs do not provide access for them. Here, I take no stance on what exactly determines whether something is excessively effortful: for the purposes of this paper, it suffices to note that we there are clear cases that illustrate that non-excessive effort is a criterion for access.

Applying the above criteria to self-control, for A to access self-control, there must be some self-control behaviours that are feasible means $M$ to self-control for agent A. The agent needs to be aware of the availability and efficacy of these means to self-control. And the effort required to enact this behaviour should not be excessive. The central claim in thinking of self-control in terms of access is that means, awareness and non-excessive effort each are modulated by barriers in the past and immediate environment in addition to differences individual biology. In what follows, I will describe how such barriers to self-control may arise.

Barriers to means and to non-excessive effort. Recall that, for the view espoused here, a large pool of processes and overt behaviours count as self-control and can sometimes be means $M$ to self-control. However, many such behaviours are not equally feasible for all. Some self-control behaviours are not feasible for some agents, whereas others may require excessive effort for some to enact.

For example, people who struggle with executive functions such as working memory, attention shifting, or inhibitory control, whether due to a neurodevelopmental disorder such as attention-deficit hyperactivity disorder, a mental disorder such as major depressive disorder, or due to lack of sleep, can be expected to encounter pronounced difficulties with intrapsychic strategies of self-control that are heavily reliant on cognitive control. Depending on the scope of their impact on executive functioning, these strategies and processes may not constitute a means $\mathrm{M}$, or else they may require excessive effort to enact.

Genetic and neurodevelopmental factors, together with complex environmental causes at multiple junctions during the developmental trajectory, together influence what sorts of behaviours are feasible for the agent from the neurobiological perspective. However, we are not passive with regard to our biological makeup. People with difficulties in executive functioning may gravitate away from attempting such intramental strategies of self-control. Depending on whether other strategies are readily available and detectable, they may gravitate towards those strategies that they can enact without excessive struggle. While environmental self-control strategies are helpful for all agents, they can be a lifeline for agents for whom enacting intramental strategies is an excessive struggle, or for whom such strategies are not feasible. 
However, whether the strategies of environmental selection and environmental manipulation constitute such a feasible means $M$ for an agent is modulated, to a great extent, by the agent's immediate circumstances, which can both enable and constrain the use of these strategies. Environmental strategies for self-control can include, for example, installing an application that blocks access to certain websites, avoiding a specific street, place or person, staying physically away from sweets when trying to cut down on sugar, setting visible reminders about one's aims, and relying on friends, colleagues, and family for reminders and support in sticking to a chosen behaviour. These strategies are apt means for agents living in some but not all circumstances: for example, agents who drive have more control over avoiding specific streets than do those who use public transport, and the presence of social strategies as means to self-control is contingent on the presence of supportive social relationships. Removing doughnuts from a company coffee room may be a good strategy for avoiding them at lunchtime, but whether making that change is feasible depends not on the intrinsic traits of the agent but on her position at the company and the company culture regarding such initiatives. When being heckled and facing an impulse to punch the heckler, walking away is a tried and tested environmental self-control strategy, but one that often is not available for prisoners.

In other words, the circumstances of the agent preclude some strategies of selfcontrol and make others excessively effortful, but these barriers to situational strategies of self-control are not equitably distributed. Nor is their distribution fully arbitrary. Rather, systemic, structural, and historical factors have contributed to a world where the options and opportunities agents have in leading their lives, including the scope of situational self-control strategies that are at their disposal, are unjustly distributed. In other words, lived circumstances generate barriers on strategies of environmental selection and manipulation, and the presence of such barriers tracks disadvantage. I do not claim all such barriers arise from disadvantage; rather, my claim is that disadvantaged agents face more such barriers than non-disadvantaged agents do.

Socioeconomic status is one such determinant of individual variance in access to means to self-control. Some of this determination is fairly obvious: for example, higher-SES people have access to more environmental strategies of self-control. They may, e.g., hire personal trainers to incentivize and remind themselves of their fitness goals or pay for other services in order to avoid contact with people and situations that they know put them at risk of self-control failure. Middle-class workplaces are also often more welcoming of environmental manipulation in the workplace, such as putting up post-its as reminders or even working from home, whereas working-class positions tend to be less flexible.

Yet it is plausible that SES furthermore impacts the feasibility and effortfulness of intrapsychic strategies of self-control. For example, socioeconomic status varies with physical and mental health, as well as with various neurocognitive capacities, such as memory, executive function, and language (Farah, 2017). This is due to known mechanisms by which environments affect the brain, including, e.g., the effects of chronic stress on physical and mental health and on neural functioning (ibid.). While the connection of executive functioning to self-control is the most straightforward owing to that inhibitory control is an executive function, all of the 
above neurocognitive capacities may modulate the extent to which an agent can enact various strategies of self-control. ${ }^{22}$ However, if fitting self-control strategies are accessible, i.e., if there are self-control strategies that satisfy the three criteria of accessibility sketched above, then differences in executive functioning need not result in diminished self-control.

Barriers to awareness. Access to self-control is often prevented by epistemic barriers. Despite the complex difficulties in feasibility and effortfulness that some agents face, described above, if we take self-control to encompass a very broad set of behaviours, in nearly all circumstances (outside of thought experiments), there factually are some such behaviours that would be feasible and non-excessively effortful for agents, and that they therefore could access if only they were aware of them. In other words, even if the conditions of means and non-excessive effort are satisfied, an agent may not be aware of the availability of the behaviours that would constitute such means, or she might not know that those behaviours constitute an effective form of self-control.

In part, these epistemic barriers arise from continued confusion surrounding selfcontrol. When self-control is discussed, it is often a 'black box': what happens in agents when they enact self-control is not expanded on. As self-control is increasingly discussed, this black box is beginning to crack open. Even so, intramental strategies continue to dominate both academic and lay discussions and views concerning what self-control is and how it is enacted. Agents struggling with self-control are ordinarily advised to make more of a mental effort, or else to think of the reasons they have for their preferred behaviour. In brief, practical advice on specific means of self-control is rarely given. When it is, the advice typically highlights intramental strategies of self-control. By contrast, while environmental selection and manipulation are often advised, e.g., in the context of goal pursuit, the information that these are de facto strategies of self-control is not readily available.

In terms of the epistemic condition for access, both past and present environment shape the extent to which we learn about various self-control strategies. There are considerable epistemic barriers that hinder the conscious learning and development of self-control strategies, despite that these strategies can be learned and taught. ${ }^{23}$ At other times, self-control strategies are learned but not consciously so, as the agent either spontaneously generates them or has slowly acclimated into them. Some selfcontrol strategies may be such that they require some practice or habituation to be effective, in which case the role of the past environment is highlighted.

However, the presence of specific self-control behaviours can be also made transparent in the immediate environment. For example, consider a campus study area where applications that allow students to block any websites that compete for their attention are pre-installed on the computers, and where there are visually captivating

\footnotetext{
${ }^{22}$ Furthermore, SES may modulate to what extent it is rational for an agent to enact self-control in the first place. A study by Miller et al. (2015) found high trait self-control to correlate with better psychosocial outcomes in youth regardless of SES, but to be correlated with faster immune cell ageing in low-SES youth, suggesting that self-control may be a double-edged sword for such youth.

23 See Mischel, Ayduk, Berman et al. (2011), Duckworth, Gendler \& Gross (2016).
} 
posters explaining how the application is used and its effectivity as a self-control strategy. A student entering such a space may not have previously been aware of this self-control strategy but will still be able to immediately utilize it with relative ease. In that case, the structuring of the immediate environment helps satisfy all three criteria for access: means, awareness, and non-excessive effort.

A further modulator of awareness is the salience of given self-control behaviours. In many situations, while multiple behaviours are feasible, only some of them are salient. Salience is situational: a strategy that an agent has been aware of in the past may simply not occur to an agent in a given situation. Salience can, however, be modulated by environmental cues as well as by habituation. ${ }^{24}$ The role of salience is highlighted in fast-paced situations where the agent may not have time to consider his various self-control options, such as a family dinner where the conversation is getting tense and he wishes to avoid an altercation. In such cases, habituation-i.e., which strategy the agent typically tries to utilize - can be a large determinant of salience.

Salience can guide agents to feasible, non-excessively effortful means, thus enabling access to self-control. But it can also misguide. The most salient means is not always an easy one, especially if the agent has only learned about means to selfcontrol that require excessive effort for them to enact. For that reason, agents whose lived environments have emphasized strategies that are a poor fit for them may be at heightened risk of self-control failure, and pronouncedly so in fast-paced situations.

The access approach has the broadest consequences when combined with a broad results view of self-control. However, since barriers to awareness modulate the extent to which agents can learn any skill, Sripada's (2020) process view, which describes self-control as a skilled sequence of cognitive control, is also compatible with the access approach. For a combined process and access view of self-control, barriers to awareness obstruct the learning of cognitive control skills and thus contribute to individual differences in self-control. Proponents of the process view who wish to help people with self-control difficulties ought to take these barriers seriously.

\section{When Access is Limited: The Case of ADHD}

In this section, I consider the implications of the access theory of self-control for a case where self-control is often limited. As mentioned above, many neurodevelopmental and mental health conditions modulate which self-control behaviours are feasible. Attention-deficit hyperactivity disorder (ADHD) is only one such condition, but I have chosen it as an example for two reasons: first, it is a fairly common disorder, and second, its symptom presentation, which spans self-control-associated difficulties across various domains from the occupational to the interpersonal, is sufficiently similar to nonclinical self-control problems for it to serve as an illustrative example (by contrast, addictive behaviour, often used as an example in philosophical

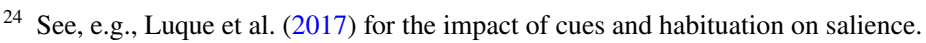


examinations of self-control, is typically described as involving self-control problems in one domain only). Second, ADHD is associated with deficits on all measures of self-control, from inhibitory control and delayed gratification to trait self-control, and its symptomology corresponds to difficulties in self-control on any theory of self-control. ${ }^{25}$

Our first puzzle is interpersonal variation in self-control in people with ADHD. The symptomology of ADHD is thought to stem from differences in executive functioning. For many people with ADHD, their disorder is reflected in self-control problems across multiple domains, resulting, e.g., in poorer work performance and unstable relationships. There is, however, plenty of anecdotal evidence of high achievers with ADHD. The claim that ADHD involves limitations in self-control may seem at odds with the observation that some people with ADHD lead careers and lives that seem to place significant demands on their self-control capacity, such as entrepreneurial and academic careers.

For the access theory, this interpersonal variation is consistent with the observation that $\mathrm{ADHD}$ is associated with problems in self-control. People with ADHD face special considerations when it comes to access to self-control: an environment that is harmless for someone without ADHD may generate barriers to self-control for someone with it. For example, environmental distractions, while annoying, can be relatively harmless for the self-control of someone without ADHD but have a pronounced detrimental effect on the self-control of someone with the disorder. ADHD may furthermore make certain self-control behaviours, such as ones that rely on inhibitory control, attention shifting, and working memory, unfeasible or excessively effortful for the agent.

However, there are other self-control behaviours that it does not impact, or on which its impact is small. These latter behaviours include many environmental strategies and might plausibly also include some intrapsychic strategies such as construal. Some people with ADHD are well placed to discover and enact self-control behaviours that are a good fit for them, and thus may form a broad enough 'toolkit' for self-control to have awareness of means to self-control that are well suited for a variety of situations. Acknowledging the efficacy of these agents' self-control strategies is consistent with emphasizing the robust adverse effects of ADHD on the selfcontrol of most people with the disorder; it furthermore implies that we ought to develop effective ways to help people with ADHD discover such self-control behaviours that are suited for these agents in the circumstances they live in.

Medication can help people with ADHD succeed in self-control tasks. However, medication does not remove ADHD-associated self-control difficulties altogether; and for some people with ADHD, suitable medication is not available. It is therefore important to also manage ADHD with non-medical means. Helping people with ADHD succeed in self-control entails facilitating situation modification strategies

\footnotetext{
${ }^{25}$ For an in-depth examination of the relationship between self-control and ADHD, see Barkley (1997). For an up-to-date overview of the disorder, see Barkley (2015). Note that the role of the environment for self-control is also emphasized in discussions of addiction and self-control, such as in the essays comprising an edited volume on the topic (Levy 2013).
} 
such as requesting frequent feedback or increased monitoring, adding visual reminders, and developing suitable situation selection strategies. ${ }^{26}$

However, there is considerable variance in to what extent strategies of situation selection and situation modification are available for people with ADHD. For example, not all people with ADHD have supportive social and occupational environments where frequent feedback and monitoring could be arranged, or sufficient control over their living space that visual reminders could be installed. Furthermore, epistemic barriers can prevent people with ADHD from engaging in these practices. Notably, the tendency of laypeople, educators, and scientists alike to emphasize intramental strategies of self-control can prevent people with ADHD from learning about situational strategies of self-control that would be a better fit for their neural makeup.

Of further interest is that socioeconomic disadvantage and ADHD are associated (Miller et al., 2015). The symptoms of ADHD generate difficulty in employment and educational achievement, due to which adults with ADHD tend to earn less than peers (ibid.). The heritability of ADHD compounds the problem: children with ADHD are statistically likely to have at least one parent with ADHD, whose educational and occupational struggles make children with ADHD more likely than peers to be born to lower income families. As SES modulates access to self-control behaviours both directly and indirectly, low-SES people with ADHD are in a double bind: not only is it harder for them to enact intramental self-control behaviours, but they also encounter epistemic barriers and lack means for situational self-control strategies due to their socioeconomic disadvantage. ${ }^{27}$

As a result, the lived circumstances of many agents with ADHD, particularly circumstances of socioeconomic disadvantage, place further special challenges on discovering and enacting feasible self-control behaviours.

Many mental and neurological disorders adversely impact the executive functions, resulting in similar barriers to self-control. However, not all such disorders are fully analogous with ADHD with respect to these barriers. For example, while ADHD is consistent with lower measures of cognitive control, Tourette's syndrome, characterized by the presence of chronic motor and vocal tics, may not be associated with problems in cognitive control. Intriguingly, Mueller et al. (2006) found greater levels of cognitive control in youth with Tourette's compared to peers in an oculomotor task: the mechanisms underlying the tics, then, are dissimilar to the mechanisms underlying ADHD-associated traits. In some disorders, their associated atypical behaviours are reflexive in character rather than resulting from failure to

\footnotetext{
${ }^{26}$ See Barkley (1997) for an account on the relationship of self-control and ADHD, and on how selfcontrol can be fostered in people with ADHD.

27 Many risks associated with ADHD also have an association with SES: while the precise mechanisms of interaction are unknown, there is some indication that the joint presence of low SES and ADHD is a larger risk factor than either of the two alone. Social risks associated with ADHD include, for example, substance use, problems in personal relationships, and problems with the law (Barkley 2015).). For example, people with ADHD are overrepresented in the criminal justice system (Koi, Uusitalo \& Tuominen 2018). Incarceration is an example of a situation where access to situational self-control strategies is markedly limited.
} 
manage motivational conflicts; theorizing about self-control has limited explanatory force in such cases.

The access theory claims that epistemic and practical barriers to situational strategies of self-control set people with ADHD (and with other disorders or lived circumstances that adversely impact their executive functioning) at a markedly disadvantaged position regarding self-control. These barriers may severely undermine the self-control of people with conditions such as ADHD, who may experience intramental strategies as unfeasible or disproportionately effortful. Barriers like these are also present for people without conditions associated with impaired executive functioning. However, their impact is smaller for people for whom intramental strategies are not such an uphill battle. The latter group of people continues to access some means to self-control even if they are prevented from accessing all such means. Yet the efficacy of environmental practices for self-control, demonstrated repeatedly in non-clinical samples, shows that if discourse on self-control were altered to emphasize environmental practices, this would benefit agents with and without ADHD alike.

Epistemic barriers are particularly hard for agents to identify because of the dimensionality of self-control impairments such as ADHD. That is, their different neurobiology may not make certain self-control practices, such as 'willpower' strategies, impossible-it merely makes them excessively effortful and difficult. As a result, one may hold on to the hope that with time, as one patiently flexes one's 'mental muscle', these difficult practices would become easier. However, knowledge of a fuller array of effective self-control behaviours would better enable these agents to seek out a 'toolkit' of means to self-control that do not entail disproportionate difficulty.

If the access theory of self-control, as described in the previous sections, is correct, then it follows that by removing barriers to self-control described here, we are not just helping people with ADHD cope with poor self-control. Rather, we are improving their self-control.

Those who remain unconvinced about the broad functionalist view of self-control presented in this paper can, nevertheless, endorse a weaker version of the access view. As mentioned above, those who accept Sripada's (2020) process view should acknowledge the role of environmental supports and constraints in developing skill in cognitive control. However, even those who reject that self-control is skilled could endorse a variation of the access view: they may claim that these environmental strategies are compensation for poor self-control rather than part of self-control yet agree that these strategies are as valuable as de facto self-control for resolving motivational conflicts. Proponents of such stances can agree with proponents of the access theory that we ought to take practical steps to enable access to such strategies.

\section{Conclusion}

For the access theory of self-control, self-control is a set of practices and behaviours. Individual differences in self-control are explained by differences in access to these practices and behaviours. Differences in access arise not just from individual 
biology but also from the past and present environment. If the access theory is true, then individual differences in self-control are not merely a matter of inherent character: they are a matter of justice. By emphasizing intramental self-control behaviours over environmental ones, present discourse on self-control obscures the availability and efficacy of environmental self-control strategies, setting people with disorders such as ADHD at a disadvantage. Yet these epistemic barriers on self-control can be alleviated by emphasizing the heterogeneity of self-control behaviours. Practical barriers, by contrast, could be lifted by adjusting practices at schools, workplaces, et cetera to allow for a wider range of environmental practices in those contexts.

Willpower approaches to self-control have contributed to obscuring the need for actively removing barriers to self-control strategies. Further research on the precise policy changes and educational practices by which access to self-control could best be improved is urgently needed.

Acknowledgements The author would like to thank two anonymous reviewers, Jaakko Kuorikoski and audiences at the Finnish Congress for Doctoral Students in Philosophy for helpful comments and feedback on earlier drafts of this paper. This research has been funded by the Finnish Cultural Foundation.

Funding Open Access funding provided by University of Turku (UTU) including Turku University Central Hospital. This article has been funded.

Open Access This article is licensed under a Creative Commons Attribution 4.0 International License, which permits use, sharing, adaptation, distribution and reproduction in any medium or format, as long as you give appropriate credit to the original author(s) and the source, provide a link to the Creative Commons licence, and indicate if changes were made. The images or other third party material in this article are included in the article's Creative Commons licence, unless indicated otherwise in a credit line to the material. If material is not included in the article's Creative Commons licence and your intended use is not permitted by statutory regulation or exceeds the permitted use, you will need to obtain permission directly from the copyright holder. To view a copy of this licence, visit http://creativecommons.org/licen ses/by/4.0/.

\section{References}

Ainslie, G. (2001). Breakdown of Will. Cambridge University Press.

Audi, R. (1991). Intention, cognitive commitment, and planning. Synthese, 86(3), 361-378.

Barkley, R. A. (1997). ADHD and the nature of self-control. Guilford Press.

Barkley, R. A. (2015). Attention-deficit hyperactivity disorder: A handbook for diagnosis and treatment (4th ed.). The Guilford Press.

Barnes, E. (2016). The minority body: a theory of disability. Oxford University Press.

Baumeister, R. F., \& Exline, J. J. (1999). Virtue, personality, and social relations: self-control as the moral muscle. Journal of Personality, 67(6), 1165-1194.

Baumeister, R. F., Vohs, K. D., \& Tice, D. M. (2007). The strength model of self-control. Current Directions in Psychological Science, 16(6), 351-355.

Cohen, J. R., Berkman, E. T., \& Lieberman, M. D. (2013). Intentional and incidental self-control in ventrolateral PFC. In D. T. Stuss \& R. T. Knight (Eds.), Principles of frontal lobe function (2nd ed., pp. 417-440). Oxford University Press.

Duckworth, A. L., Gendler, T. S., \& Gross, J. J. (2016). Situational strategies for self-control. Perspectives on Psychological Science, 11(1), 35-55.

Duckworth, A. L., \& Kern, M. L. (2011). A meta-analysis of the convergent validity of self-control measures. Journal of Research in Personality, 45(3), 259-268.

Farah, M. J. (2017). The neuroscience of socioeconomic status: Correlates, causes, and consequences. Neuron, 96(1), 56-71. 
Fujita, K. (2011). On conceptualizing self-control as more than the effortful inhibition of impulses. Personality and Social Psychology Review, 15(4), 352-366.

Fujita, K., Carnevale, J. J., \& Trope, Y. (2018). Understanding self-control as a whole vs. part dynamic. Neuroethics, 11(3), 283-296.

Gray, R. (2009). A model of motor inhibition for a complex skill: Baseball batting. Journal of Experimental Psychology: Applied, 15(2), 91-105.

Hagger, M. S., Chatzisarantis, N. L. D., Alberts, H., et al. (2016). A multilab preregistered replication of the ego-depletion effect. Perspectives on Psychological Science, 11(4), 546-573.

Henden, E. (2008). What is self-control? Philosophical Psychology, 21(1), 69-90.

Herdova, M. (2017). Self-control and mechanisms of behavior: Why self-control is not a natural mental kind. Philosophical Psychology, 30(6), 731-762.

Holton, R. (2003). How is strength of will possible? In S. Stroud \& C. Tappolet (Eds.), Weakness of Will and Practical Irrationality (pp. 39-67). Oxford University Press.

Horstkötter, D. (2015). Self-control and normativity: Theories in social psychology revisited. Theory \& Psychology, 25(1), 25-44.

Inzlicht, M., \& Friese, M. (2019). The past, present, and future of ego depletion. Social Psychology, 50, $370-378$.

Kalis, A. (2018). Self-control as a normative capacity. Ratio, 31(S1), 65-80.

Kennett, J. (2001). Agency and Responsibility: A Common-Sense Moral Psychology. Oxford University Press.

Koi, P. (2021). Born which way? ADHD, situational self-control, and responsibility. Neuroethics, 14, 205-218.

Koi, P., Uusitalo, S., \& Tuominen, J. (2018). Self-control in responsibility enhancement and criminal rehabilitation. Criminal Law and Philosophy, 12(2), 227-244.

Levy, N. (2011). Resisting weakness of will. Philosophy and Phenomenological Research, 82(1), $134-155$.

Levy, N. (Ed.). (2013). Addiction and self-control: perspectives from philosophy, psychology, and neuroscience. Oxford University Press.

Levy, N. (2017). Of marshmallows and moderation. In W. Sinnott-Armstrong \& C. B. Miller (Eds.), Moral psychology: Virtue and character (Vol. 5, pp. 197-213). MIT Press.

Luque, D., Beesley, T., Morris, R. W., Jack, B. N., Griffiths, O., Whitford, T. J., \& Le Pelley, M. E. (2017). Goal-directed and habit-like modulations of stimulus processing during reinforcement learning. The Journal of Neuroscience, 37(11), 3009-3017.

Mele, A. R. (1987). Irrationality: An essay on akrasia, self-deception, and self-control. Oxford University Press.

Mele, A. R. (1995). Autonomous agents: From self-control to autonomy. Oxford University Press.

Miller, G. E., Yu, T., Chen, E., \& Brody, G. H. (2015). Self-control forecasts better psychosocial outcomes but faster epigenetic aging in low-SES youth. PNAS, 112(33), 10325-10330.

Miller, L. L., Gustafsson, H. C., Tipsord, J., Song, M., Nousen, E., Dieckmann, N., \& Nigg, J. T. (2018). Is the association of ADHD with socio-economic disadvantage explained by child comorbid externalizing or parent ADHD? Journal of Abnormal Child Psychology, 46(5), 951-963.

Mischel, W., Ayduk, O., Berman, M. G., et al. (2011). 'Willpower' over the life span: Decomposing selfregulation. Social Cognitive and Affective Neuroscience, 6(2), 252-256.

Mischel, W., \& Ebbesen, E. B. (1970). Attention in delay of gratification. Journal of Personality and Social Psychology, 16, 329-337.

Mueller, S. C., Jackson, G. M., Dhalla, R., Datsopoulos, S., \& Hollis, C. P. (2006). Enhanced cognitive control in young people with Tourette's syndrome. Current Biology, 16(6), 570-573.

Muraven, M., \& Baumeister, R. (2000). Self-regulation and depletion of limited resources: does selfcontrol resemble a muscle? Psychological Bulletin, 126(2), 247-259.

Oliver, M. (1996). Understanding disability: From theory to practice. Macmillan.

Shakespeare, T. (2006). Disability rights and wrongs. Routledge.

Sripada, C. S. (2014). How is willpower possible? The puzzle of synchronic self-control and the divided mind. Noûs, 48(1), 41-47.

Sripada, C. S. (2020). The atoms of self-control. Noûs. https://doi.org/10.1111/nous.12332

Stein, R. B., Gossen, E. R., \& Jones, K. E. (2005). Neuronal variability: Noise or part of the signal? Nature Reviews Neuroscience, 6, 389-397.

Tangney, J. P., Baumeister, R. F., \& Boone, A. L. (2004). High self-control predicts good adjustment, less pathology, better grades, and interpersonal success. Journal of Personality, 72(2), 271-324. 
Tremain, S. L. (2015). Foucault and feminist philosophy of disability. University of Michigan Press.

Vohs, K., Schmeichel, B., Lohmann, S., Gronau, Q. F., Finley, A. J., Others, M., \& Albarracín, D. (2021). A multi-site preregistered paradigmatic test of the ego depletion effect. Psychological Science, 32(10), 1566-1581.

Publisher's Note Springer Nature remains neutral with regard to jurisdictional claims in published maps and institutional affiliations. 